\title{
Separation of the Mixture 2-Propanol + Water by Heterogeneous Azeotropic Distillation with Isooctane as an Entrainer
}

\author{
Giorgia De Guido *(D), Chiara Monticelli, Elvira Spatolisano and Laura Annamaria Pellegrini \\ GASP-Group on Advanced Separation Processes \& GAS Processing, Dipartimento di Chimica, \\ Materiali e Ingegneria Chimica "G. Natta", Politecnico di Milano, Piazza Leonardo da Vinci 32, \\ I-20133 Milano, Italy; chiara.monticelli@mail.polimi.it (C.M.); elvira.spatolisano@polimi.it (E.S.); \\ laura.pellegrini@polimi.it (L.A.P.) \\ * Correspondence: giorgia.deguido@polimi.it
}

check for updates

Citation: De Guido, G.; Monticelli, C.; Spatolisano, E.; Pellegrini, L.A. Separation of the Mixture 2-Propanol + Water by Heterogeneous Azeotropic Distillation with Isooctane as an Entrainer. Energies 2021, 14, 5471. https://doi.org/10.3390/en14175471

Academic Editors: Nguyen Van Duc Long, Moonyong Lee and Le Cao Nhien

Received: 30 July 2021

Accepted: 29 August 2021

Published: 2 September 2021

Publisher's Note: MDPI stays neutral with regard to jurisdictional claims in published maps and institutional affiliations.

Copyright: (c) 2021 by the authors. Licensee MDPI, Basel, Switzerland. This article is an open access article distributed under the terms and conditions of the Creative Commons Attribution (CC BY) license (https:/ / creativecommons.org/licenses/by/ $4.0 /)$.

\begin{abstract}
Advanced processes, which are alternatives to ordinary distillation, are essential to dehydrate azeotropic alcoholic mixtures for biofuel production. In that regard, this work focuses on the analysis of heterogeneous azeotropic distillation for the separation of a 2-propanol + water mixture in order to recover the alcohol with a sufficiently low water content. By comparing the performances of various entrainers on the basis of ternary maps, isooctane was selected for further process analysis. An advantage it poses is related to the fact that traces of it within the recovered dehydrated alcohol are highly welcome with a view to its subsequent use as a fuel. Aspen Plus ${ }^{\circledR}$ V11 software was employed for the simulation of the process, thus filling the gap existing in the literature due to the lack of studies on the process analysis of the heterogeneous azeotropic distillation of the 2-propanol + water system using isooctane as an entrainer.
\end{abstract}

Keywords: alcohols; azeotropes; biofuels; dehydration; heterogeneous azeotropic distillation; isooctane; 2-propanol; water

\section{Introduction}

The need for reducing the consumption of fossil fuels and increasing the use of renewable energy has caused a growing interest in biofuels. In particular, alcoholic mixtures resulting from bioprocesses can be effectively used as fuel substitutes or additives with a view to increasing the octane number, ensuring a better combustion, reducing harmful exhaust pipe emissions, and thus protecting the environment. Indeed, light alcohols are directly used as a blendstock with gasoline in many countries such as Brazil, Europe and the USA [1]. Among them, ethanol and butanol can be mentioned, which have been proven to reduce life-cycle greenhouse gas emissions when produced from biomass and waste feedstock [2], though some problems are encountered when operating these processes [3,4], and high costs are involved in the downstream product recovery [5,6]. According to Zhu et al. [7], bioethanol recovery from fermentation broths involves energy consumptions that account for $60-80 \%$ of the total biofuel production consumption. In that regard, an important aspect to be taken into account is related to the concentration and final dehydration of the fermentation broth, which affect the price of the alcohol product, especially if a high purity is required, as for direct combustion or gasoline mixing purposes [8]. Indeed, even tiny amounts of water within the blend can lead to phase splitting, which in turn can cause engine troubles and malfunctions. For example, in fuel-grade ethanol the presence of water affects the physicochemical properties of ethanol-biodiesel blend fuels, with a negative impact on their combustion [9]. Hence, the dehydration of azeotropic alcoholic mixtures represents a crucial step for biofuel production, and alternative processes to ordinary distillation need to be found.

Vacuum distillation, extractive distillation, heterogeneous azeotropic distillation, liquid-liquid extraction including salting-out extraction [10], pervaporation [11] and ad- 
sorption are examples of the possible advanced technologies required to obtain alcoholic fractions with sufficiently low water contents. Among them, the extractive distillation (ED) and the heterogeneous azeotropic distillation (HAD) processes represent the most commonly employed and competitive options for anhydrous alcohol production. HAD, in particular, is a widely used technique to separate azeotropic alcoholic mixtures into their components: in such a process, an additional compound, called entrainer, causes liquidliquid phase separation over a broad range of compositions in the ternary phase diagrams. This liquid-liquid phase split allows us to move across the distillation boundaries caused by the existence of azeotropes within the mixture.

In that regard, it is important to point out that the choice of the entrainer to be added is a key aspect: various factors, including safety, environmental effects, corrosion, availability and price, need to be taken into consideration. In addition, major concerns are represented by the analysis of the structure of the residue curves and distillation line maps associated with the resulting mixtures [12,13].

Several studies have been published on the subject of HAD, with particular reference to advantages and disadvantages, heterogeneous phase diagrams, residue curve maps and column sequencing [12,14-20]. Furthermore, the optimization, dynamics and control of the process configuration have been addressed [21-26].

More in depth, several papers are available with reference to HAD processes for the dehydration of alcoholic mixtures. In particular, in the case of ethanol + water mixtures, the solvents which are typically employed are isooctane, benzene and toluene: practical examples of ethanol dehydration with the use of isooctane as an entrainer have been analyzed by Cairns and Furzer [27], as well as Font and co-workers [28]. A two-column sequence, for instance, has been envisaged in case the ethanol is to be used as a fuel: by means of such a process configuration, a mixture containing ethanol and isooctane is obtained, meeting the ASTM specifications given by the American Society for Testing and Materials for an ethanol-based fuel E95. In parallel, Gomis et al. [29] have analyzed the viability of a HAD process with isooctane as an entrainer to dehydrate ethanol and to obtain a mixture of ethanol + isooctane, for use as gasoline and with a water concentration lower than $50 \mathrm{ppm}$. The attention of the authors was particularly focused on the importance of the thermodynamic model to be used to carry out the simulations: as a matter of fact, the model has to accurately predict the phase splitting, and possible differences between experimental and simulation results can be attributed to the inappropriate calculation of the liquid-liquid equilibria (LLE).

Regarding cases in which benzene and toluene are employed as entrainers for ethanol dehydration processes, various studies have been published [18,20,24,30,31]. With specific reference to Luyben's work and analysis [24], rigorous simulations of the process, involving a preconcentrator, the azeotropic and entrainer recovery column, have been carried out by means of Aspen Plus ${ }^{\circledR}$ : as emphasized in the paper, the simulation of the first preconcentration column is not critical. Instead, the same is not true for the other two columns involved because of the two associated recycle streams: converging recycle streams is quite often very difficult, especially when considering a highly non-ideal phase equilibrium system. Moreover, multiple steady states can be found, depending on the initial values considered for the various parameters.

In addition to isooctane, benzene and toluene, various other hydrocarbons can be regarded as candidate entrainers for ethanol dehydration processes. As a matter of fact, systems composed of ethanol, water and hydrocarbons are extremely important in the fuel industry, where ethanol + gasoline blends, with sufficiently low amounts of water, are widely employed. Thus, the use of a hydrocarbon as an entrainer has the advantage that any remaining quantity within the recovered alcoholic fraction would not pose a problem for its subsequent use as a fuel. For instance, Gomis and co-workers [32,33] have analyzed the vapor-liquid-liquid equilibria (VLLE) and the vapor-liquid equilibria (VLE) for ethanol + water + heptane and the ethanol + water + hexane systems. Besides this, Pequenín et al. [34-36] have investigated the VLLE and the VLE behavior of various 
systems involving ethanol, water and various hydrocarbons as solvents (cyclohexane, heptane, isooctane, toluene). In the end, as suggested by Pienaar [30], diisopropyl ether (DIPE) can also be considered as a feasible entrainer in the case of ethanol dehydration by HAD processes.

With reference to 2-propanol + water mixtures, instead, the commonly employed entrainers are cyclohexane and benzene. Chien and co-workers [37] have shown two different and feasible column sequences to obtain a 2-propanol product stream when starting from an aqueous alcoholic mixture (69\% mol 2-propanol and 31\% mol water). Additionally, in the case of a more diluted 2-propanol + water mixture, Arifin and Chien [38], as well as Luyben and Chien [39], have analyzed and optimized different column sequences with the use of cyclohexane as an entrainer.

Further studies on the subject of 2-propanol dehydration processes with cyclohexane or benzene as an entrainer have been published [15,21,22,26,30,40]. In addition, DIPE can be envisaged as a possible entrainer [30], while other studies are related to the potentiality of using isooctane for the separation of 2-propanol + water mixtures [41,42], analysing phase equilibria.

Tables 1 and 2 summarize the entrainers that have been considered in the literature works for the separation of the ethanol + water mixture (Table 1) and 2-propanol + water mixture (Table 2), focusing either on thermodynamic equilibrium measurements or on the proposal of separation sequences.

Further papers related to HAD for the separation of aqueous alcoholic mixtures can also be mentioned [30,43-55]. Gomis et al. [43], for instance, have analyzed the $n$-butanol + water $+n$-hexane system, whilst Pienaar et al. [44] have considered the VLLE and the VLE for the ternary systems n-propanol + water + DIPE and n-propanol + water + isooctane. Indeed, alternative entrainers to the carcinogenic benzene need to be found. Consequently, hydrocarbons such as hexane to octane and their isomers have been proposed as candidates, with cyclohexane being the most popular one. Additionally, common fuel additives such as DIPE and di-n-propyl ether (DNPE) have also been recommended. In the end, many studies which are related to the VLLE and VLE of aqueous alcoholic mixtures and amyl alcohol (1-pentanol) as a possible entrainer have been published [52,56-60].

The present paper focuses on the separation process of a 2-propanol + water mixture by means of an HAD process, as this has been investigated less than the ethanol + water mixture, particularly from a process point of view. As a matter of fact, when considering mixtures obtained from bioprocesses, 2-propanol is one of the most abundant alcoholic components.

At first, relying on what is available in the scientific literature on the subject, various candidate entrainers have been identified and their performances have been compared on the basis of ternary maps. Once isooctane was identified as the most appropriate solvent for the separation, process simulations were carried out with AspenTech's Aspen Plus ${ }^{\circledR}$ V11 [61] commercial simulation software using the Non-Random Two-Liquid (NRTL) thermodynamic model with built-in parameters. Ultimately, with particular reference to the HAD, the present paper is intended to fill the gap due to the lack, in the pertinent literature, of works focused on the dehydration of aqueous 2-propanol mixtures with the use of isooctane as an entrainer. Indeed, most of the literature is centred on HAD processes with the use of isooctane for the separation of ethanol + water mixtures. On the other hand, HAD processes for the dehydration of aqueous 2-propanol mixtures typically involve benzene or cyclohexane as solvents. Moreover, the few papers available on 2-propanol + water + isooctane ternaries are related to the study of phase equilibria for the exploitation of the potential of such an entrainer for 2-propanol dehydration, without reference to process analysis. It is also important to highlight that the use of isooctane as an entrainer can be extremely beneficial in the case of 2-propanol dehydration: traces of such an entrainer do not pose a problem within the recovered dehydrated alcoholic product with a view to its subsequent use as a fuel. 
Table 1. List of entrainers considered in the literature for the dehydration of ethanol.

\begin{tabular}{|c|c|c|}
\hline Entrainer & Literature Source & Focus of the Study \\
\hline \multirow[t]{3}{*}{ benzene } & Cairns and Furzer [27] & $\begin{array}{l}\text { New simulation method for } \\
\text { three-phase distillation using a } \\
\text { modified phase-stability analysis }\end{array}$ \\
\hline & Luyben [24] & Process simulation \\
\hline & Pienaar [30] & Process simulation \\
\hline cyclohexane & Gomis et al. [45] & VLE and VLLE data \\
\hline \multirow{2}{*}{ toluene } & Gomis et al. [62] & VLE and VLLE data \\
\hline & Zhao et al. [31] & Process simulation \\
\hline \multirow{3}{*}{$\begin{array}{c}\text { isooctane or } \\
\text { 2,2,4-trimethylpentane }\end{array}$} & Cairns and Furzer [27] & $\begin{array}{l}\text { New simulation method for } \\
\text { three-phase distillation using a } \\
\text { modified phase-stability analysis }\end{array}$ \\
\hline & Font et al. [28] & VLE and VLLE data \\
\hline & Gomis et al. [29] & $\begin{array}{l}\text { Analysis of process viability by an } \\
\text { experimental procedure and an } \\
\text { equilibrium-model-based simulation }\end{array}$ \\
\hline cyclohexane + toluene & Pequenín et al. [36] & VLE and VLLE data \\
\hline cyclohexane + isooctane & Pequenín et al. [34] & VLE and VLLE data \\
\hline \multirow[t]{2}{*}{ cyclohexane + heptane } & Pequenín et al. [35] & VLE and VLLE data \\
\hline & Hwang et al. [49] & LLE data \\
\hline \multirow[t]{2}{*}{ diisopropyl ether (DIPE) } & Pienaar [30] & $\begin{array}{l}\text { VLE and VLLE data; process } \\
\text { simulation }\end{array}$ \\
\hline & Pienaar et al. [44] & VLE and VLLE data \\
\hline diethyl ether & Gomis et al. [63] & VLLE data \\
\hline pentane & Magnussen et al. [64] ${ }^{1}$ & Simulation method ${ }^{1}$ \\
\hline hexane & Gomis et al. [33] & VLE and VLLE data \\
\hline n-heptane & Gomis et al. [32] & VLE and VLLE data \\
\hline \multirow[t]{2}{*}{ p-xylene } & Gomis et al. [46] & VLE and VLLE data \\
\hline & Newsham and Vahdat [65] & VLE data \\
\hline \multirow{2}{*}{ n-butanol } & Gomis et al. [63] & VLLE data \\
\hline & Iwakabe and Kosuge [66] & VLLE data \\
\hline 2-butanol & Iwakabe and Kosuge [66] & VLLE data \\
\hline \multirow[t]{2}{*}{ 1-pentanol } & $\begin{array}{l}\text { Fernandez-Torres et al. } \\
\text { [58] }\end{array}$ & LLE data \\
\hline & $\begin{array}{l}\text { Van Zandijcke and } \\
\text { Verhoeye [67] }\end{array}$ & VLE data \\
\hline \multirow[t]{3}{*}{ ethyl acetate } & Lee et al. [68] & VLE and VLLE data \\
\hline & Gomis et al. [63] & VLLE data \\
\hline & Donis et al. [69] & $\begin{array}{l}\text { Feasibility of heterogeneous } \\
\text { batch-extractive distillation }\end{array}$ \\
\hline n-butyl acetate & Younis et al. [70] & VLLE data \\
\hline methyl ethyl ketone & Younis et al. [70] & VLLE data \\
\hline
\end{tabular}

${ }^{1}$ as reported by Cairns and Furzer [27].

Table 2. List of entrainers considered in the literature for the dehydration of 2-propanol.

\begin{tabular}{|c|c|c|}
\hline Entrainer & Literature Source & Focus of the Study \\
\hline \multirow[t]{3}{*}{ benzene } & Cho and Jeon [40] & Process simulation \\
\hline & Verhoeye [54] & VLE and LLE data \\
\hline & Prokopakis et al. [71] ${ }^{1}$ & Simulation method ${ }^{1}$ \\
\hline \multirow[t]{2}{*}{ cyclohexane } & Wang et al. [26] & $\begin{array}{l}\text { Experiment using a laboratory-scale } \\
\text { sieve plate distillation column; } \\
\text { dynamic simulation }\end{array}$ \\
\hline & Chien et al. [21] & $\begin{array}{c}\text { Dynamics and control of a HAD } \\
\text { column }\end{array}$ \\
\hline
\end{tabular}


Table 2. Cont.

\begin{tabular}{|c|c|c|}
\hline Entrainer & Literature Source & Focus of the Study \\
\hline \multirow{9}{*}{$\begin{array}{c}\text { Isooctane or } \\
\text { 2,2,4-trimethylpentane }\end{array}$} & Chien et al. [22] & $\begin{array}{c}\text { Operation and decoupling control of } \\
\text { a heterogeneous azeotropic } \\
\text { distillation column }\end{array}$ \\
\hline & Chien et al. [37] & $\begin{array}{c}\text { Design and control of a complete } \\
\text { HAD column }\end{array}$ \\
\hline & Arifin and Chien [38] & $\begin{array}{l}\text { Combined preconcentrator/recovery } \\
\text { column design }\end{array}$ \\
\hline & Kraemer et al. [15] & Shortcut-based design \\
\hline & Arda and Sayar [41] & LLE data \\
\hline & Otero et al. [42] & LLE data \\
\hline & Font et al. [72] & VLE and VLLE data \\
\hline & Rastegar and Jessen [51] & LLE data \\
\hline & This work & Process simulation \\
\hline & Hwang et al. [49] & LLE data \\
\hline \multirow[t]{2}{*}{ diisopropylether (DIPE) } & Lladosa et al. [50] & VLLE data \\
\hline & Pienaar [30] & Process simulation \\
\hline dichloromethane & Sayar [52] & LLE data \\
\hline 1,2-dichloroethane & Sayar [52] & LLE data \\
\hline 2-methylbutyl acetate & Sayar [52] & LLE data \\
\hline 1-butanol & Aicher et al. [73] & VLE and LLE data \\
\hline 1-pentanol & Sayar [52] & LLE data \\
\hline phenylmethanol & Sayar [52] & LLE data \\
\hline cyclohexanol & Sayar [52] & LLE data \\
\hline 1-methylcyclohexanol & Sayar [52] & LLE data \\
\hline dibenzyl ether & Sayar [52] & LLE data \\
\hline octanenitrile & Sayar [52] & LLE data \\
\hline
\end{tabular}

${ }^{1}$ as reported by Cairns and Furzer [27].

\section{Methods}

HAD can be reasonably regarded as a valuable option for the separation of the 2propanol + water mixture. Indeed, the presence of a homogeneous azeotrope at $80.18{ }^{\circ} \mathrm{C}$ and with $67.2 \% \mathrm{~mol} 2$-propanol hampers the separation of the two components by means of ordinary distillation, and the HAD process can be effectively employed for the separation to be accomplished.

Aspen Plus ${ }^{\circledR}$ V11 [61, AspenTech, Burlington, MA, USA] has been identified as the most suitable software because of the ability of its thermodynamic package, NRTL, to accurately reproduce the experimental equilibrium data for the operating conditions of interest, with low pressures and a highly non-ideal liquid phase. In addition, the data bank of the built-in NRTL parameters for the system under study, also considering the selected candidate entrainers, is complete.

Firstly, it was used to build ternary maps which help in the selection of the entrainer to be used in the separation of the 2-propanol + water mixture by HAD. Then, it was employed for the simulation of the process that aims at the separation of a mixture of the two components comprising $65 \% \mathrm{~mol} 2$-propanol, which is assumed to be near the 2-propanol and water azeotropic composition. As illustrated in the schematic flowsheet in Figure 1, the process consists of two columns, namely the HAD column (COLUMN 1) and the entrainer recovery column (COLUMN 2), which have, respectively, 30 and 25 equilibrium stages and are operated at atmospheric pressure. The first column, into which the fresh feed (FF), the distillate from the recovery column (D2) and the organic reflux (OR) from the DECANTER are fed, separates pure 2-propanol at the bottom (B1) and the top vapour $V 1$ close to the ternary azeotrope. The organic phase exiting the DECANTER, which contains mostly the entrainer, is totally refluxed back to the HAD column, while the aqueous phase (AO, aqueous outlet), still containing a significant amount of 2-propanol, is fed into the recovery column. The bottom stream (B2) of this column is pure water, and the distillate (D2) is recycled back to the HAD column. In the first column, the mass 
purity of the bottom product B1 was set equal to $99.75 \%$, so as to limit the water content to $2500 \mathrm{ppm}$ by weight. As for the second column, the mole purity of the bottom product B2, rich in water, was set equal to $99.95 \%$ for limiting the impact on the downstream water treatment process. In order to obtain an indication about this, the Theoretical Oxygen Demand (ThOD) for the aqueous stream exiting the separation process was computed: such a parameter, corresponding to the amount of oxygen required to completely oxidize the organic components within the stream, provides an indication of the carbon yield of the separation process, as well as of the impact on the downstream water treatment process. As a matter of fact, the higher the ThOD value, the higher the carbon content within the aqueous stream and the worse it is in terms of the carbon yield of the separation process. Moreover, if ThOD values are too high, the aqueous stream weighs too much on the downstream water treatment process. In this work, a maximum value of $3-4 \mathrm{gO}_{2} / \mathrm{L}$ was considered as the target for the process simulation so as not to burden the water purification process. The two specifications for the 2-propanol product and water product have been achieved in the simulation by varying the flow rate of the bottom product of the respective columns. More details about the set-up of the simulation are reported in the Section 3.2.

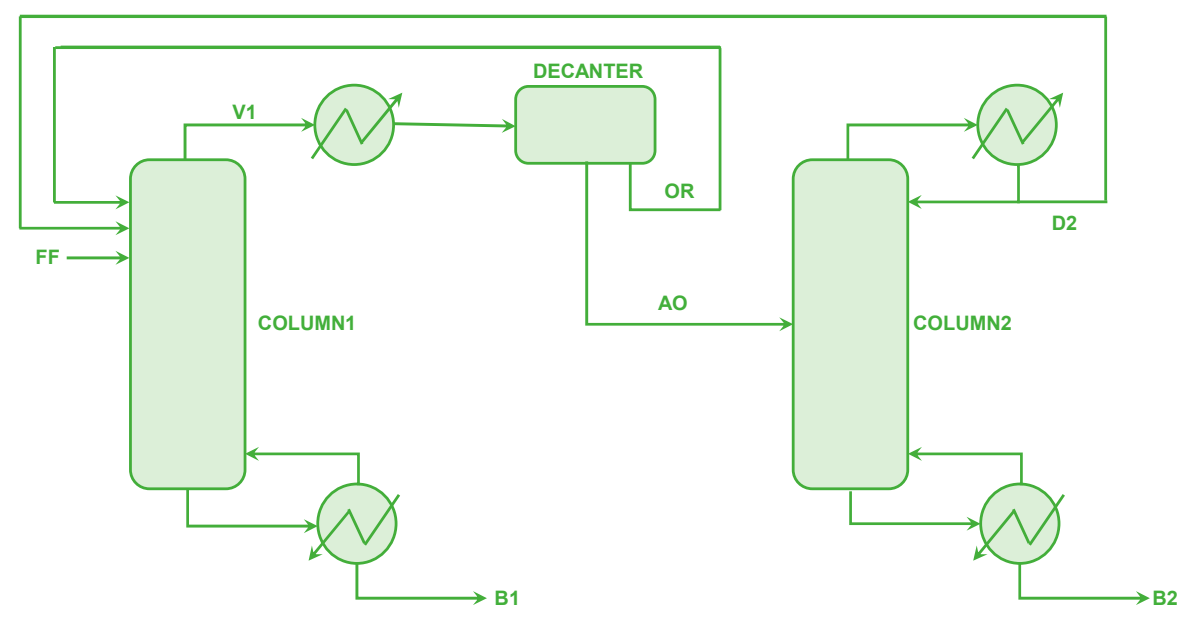

Figure 1. Scheme of the heterogeneous azeotropic separation of the 2-propanol + water mixture: $\mathrm{AO}$, aqueous phase exiting the decanter; B1, bottom product of COLUMN 1; B2, bottom product of COLUMN2; COLUMN1, heteroazeotropic distillation column; COLUMN2, entrainer recovery column; D2, distillate product of COLUMN2; FF, fresh feed; OR, organic phase exiting the DECANTER; V1, vapor stream exiting the top of COLUMN1.

\section{Results}

This section deals with the results obtained for the selection of the entrainer (Section 3.1) and for the process simulation carried out using isooctane as an entrainer (Section 3.2).

\subsection{Entrainer Selection}

As was thoroughly shown in the introductory paragraph, the typical solvents used for the separation of azeotropic mixtures involving 2-propanol and water are benzene and cyclohexane $[24,37,38,40]$. Nevertheless, isooctane can be potentially considered as a suitable entrainer for the separation of aqueous 2-propanol solutions: ternary 2-propanol + water + isooctane mixtures have been analyzed, and the extracting capability of the entrainer was estimated by making reference to distribution coefficients and separation factors $[41,42,51,55]$. In that regard, it is also necessary to mention that, unlike the commonly employed benzene, isooctane is not carcinogenic. Moreover, as was previously mentioned, traces of such an entrainer, which is a typical hydrocarbon in gasoline, are useful within the recovered 2-propanol fraction with a view to its subsequent use as a fuel. Hence, the purity requirements for the dehydrated 2-propanol product fraction do not need to be extremely tight $[29,32,34-36,43,44]$. In addition, amyl alcohol can also be considered as 
a candidate entrainer for the separation of 2-propanol + water mixtures, considering the relevant literature on phase equilibria [56-60].

In order to compare the performances of the various entrainers, ternary maps showing the heterogeneous azeotrope point, the liquid-liquid phase splitting region and the associated tie lines have to be considered. Figures $2-4$ represent such diagrams, respectively, in case of the systems 2-propanol + water + benzene, 2-propanol + water + cyclohexane, and 2-propanol + water + isooctane.

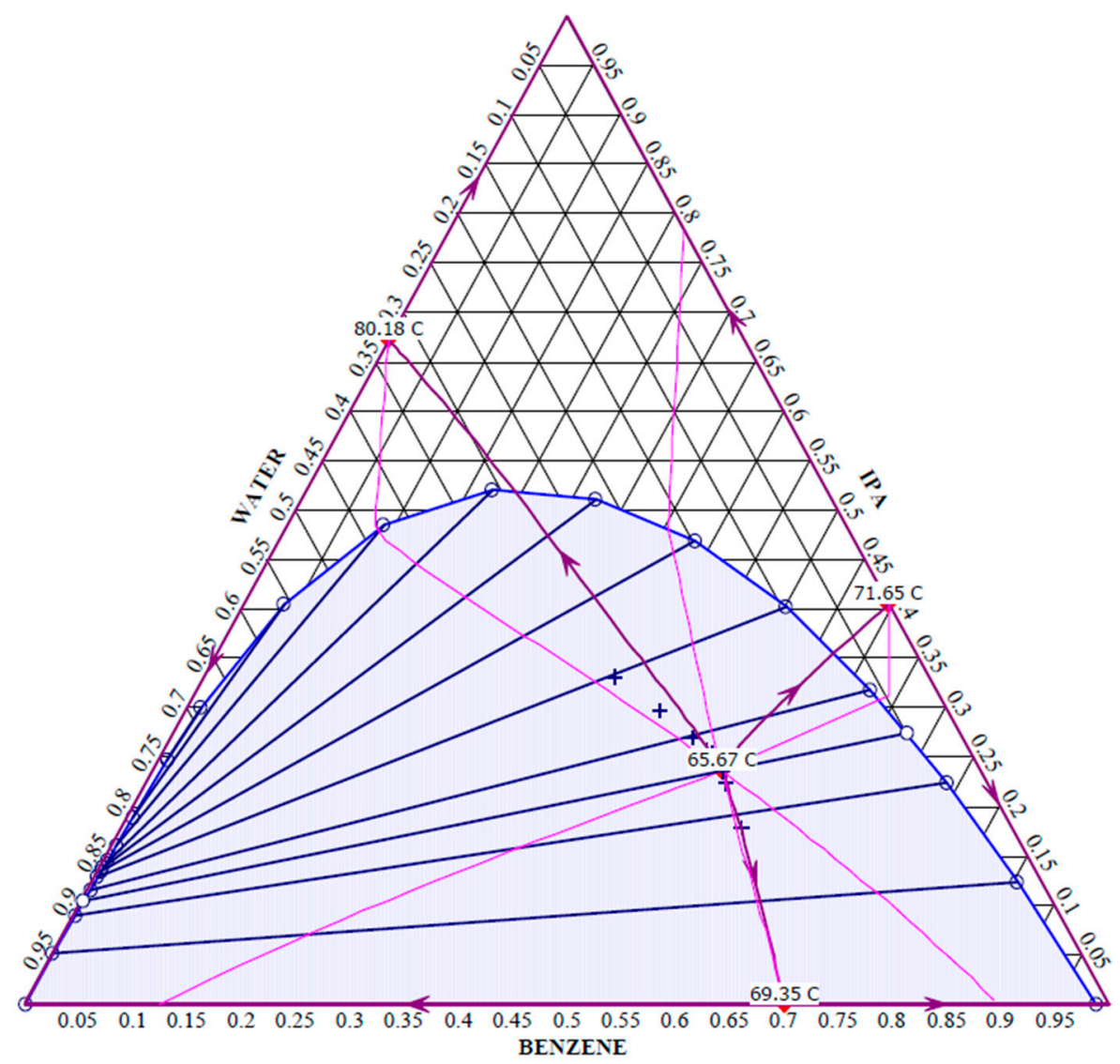

Figure 2. Ternary map at $1 \mathrm{~atm}$, obtained by means of Aspen Plus ${ }^{\circledR}$ V11 [61] using the NRTL model, for the system 2-propanol (IPA) + water (WATER) + benzene (BENZENE).

According to Luyben and Chien [39], the comparison of entrainers' performances has to be carried out by making particular reference to the material balance lines associated with the process inside the ternary maps. As a matter of fact, if we are considering an ideal case, as illustrated in Figure 1, for the separation of the fresh feed (FF), the bottom stream (B1) of the heteroazeotropic column (COLUMN1) reaches the composition of pure 2-propanol, whilst the top vapor stream (V1) approaches the ternary azeotrope. The stream $\mathrm{D} 2$, instead, exiting the top of the recovery column, is located at the distillation boundary. Thus, with reference to such an ideal case, the flowrate of the vapor stream from the top of the heterogeneous azeotropic column can be estimated by means of Equation (1), where $b$ and $a$ are obtained by drawing a line between the summation point FF $+\mathrm{D} 2$ and the organic reflux exiting the decanter (OR), and a line between $B 1$ and $V 1$ inside the ternary diagram:

$$
\text { V1 flowrate }=B 1 \text { flowrate } \times \frac{b}{a}
$$




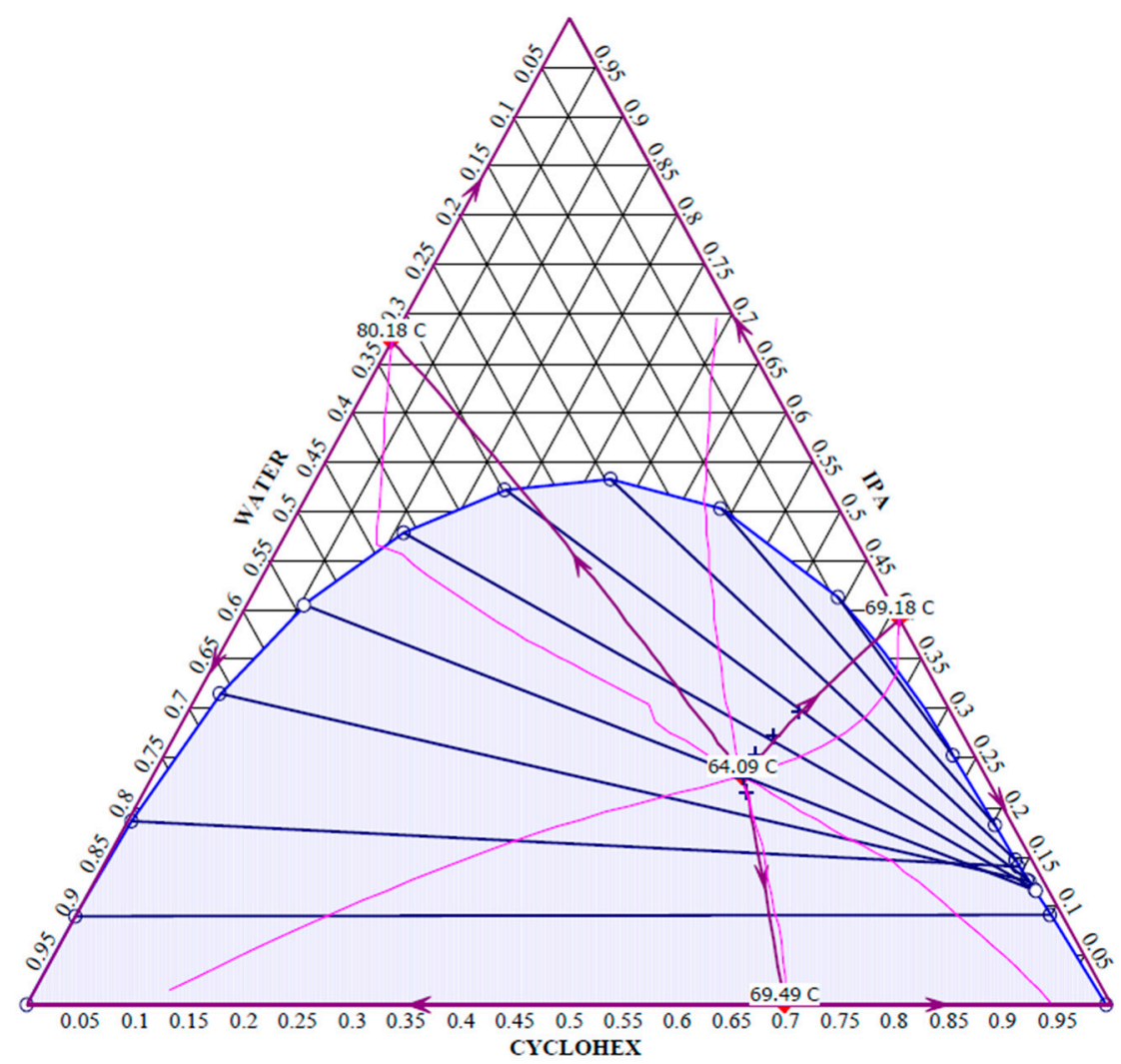

Figure 3. Ternary map at $1 \mathrm{~atm}$, obtained by means of Aspen Plus ${ }^{\circledR}$ V11 [61] using the NRTL model, for the system 2-propanol (IPA) + water (WATER) + cyclohexane (CYCLOHEX).

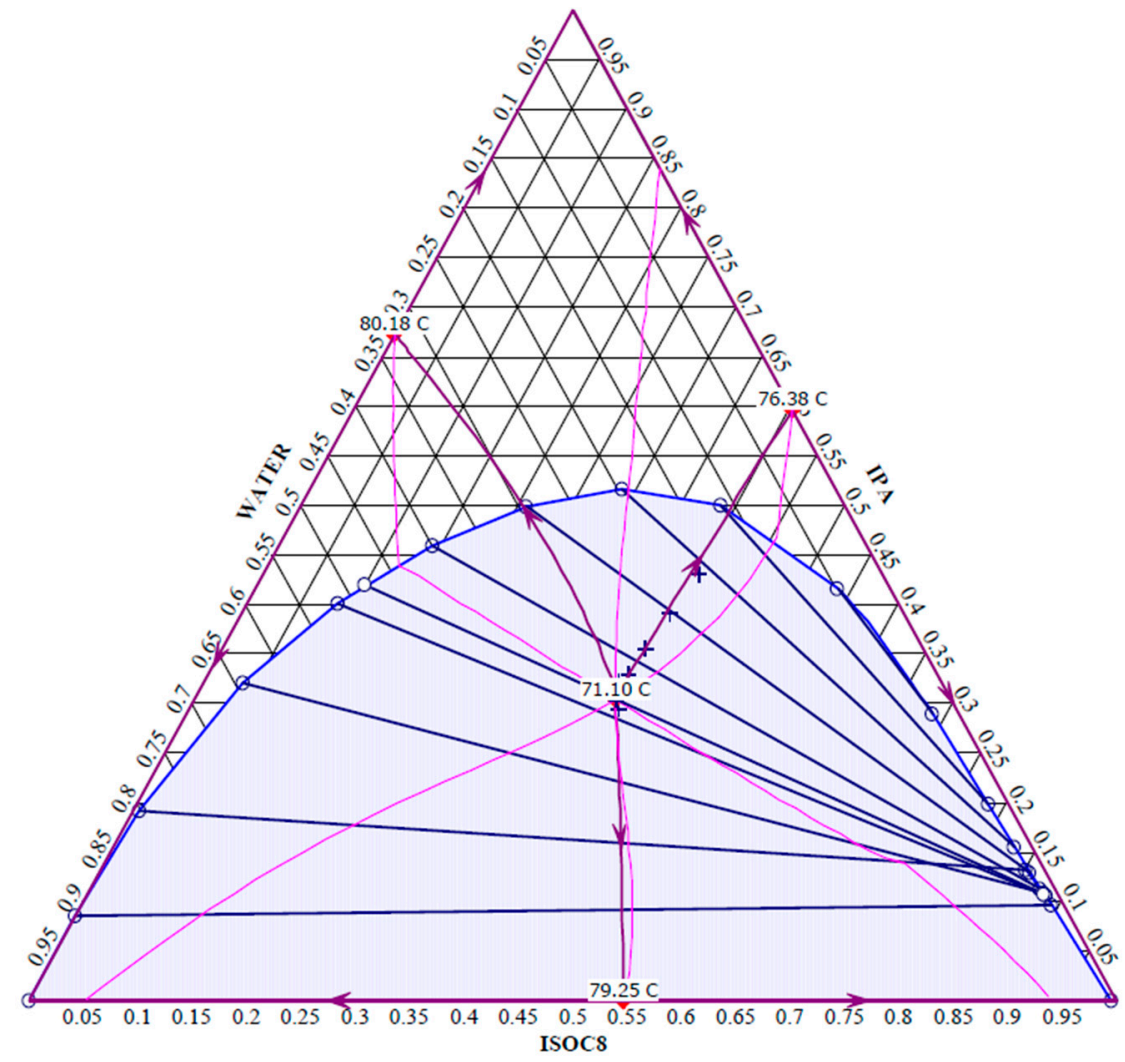

Figure 4. Ternary map at $1 \mathrm{~atm}$, obtained by means of Aspen Plus ${ }^{\circledR}$ V11 [61] using the NRTL model, for the system 2-propanol (IPA) + water (WATER) + isooctane (ISOC8). 
As a consequence, the position of the ternary azeotropic point and the slope of the tie line passing through it are fundamental. Indeed, the estimated vapor flowrate is much lower if the ternary heterogeneous azeotrope is located lower and if the OR point is placed more favorably in the ternary diagram, i.e., so that the material balance line drawn from the point of FF + D2 to the point of OR is such that it is not very closed to the point of the ternary azeotrope, which would lead to a greater top vapor flowrate from the lever rule. As a result of a lower vapor flowrate from the HAD column, a lower OR flowrate is sent back to the heterogeneous azeotropic column, and a much lower flowrate of the aqueous stream $(\mathrm{AO})$ exits the decanter and enters the entrainer recovery column. In other terms, less reboiler duty is required to generate the boil-up, and smaller diameters are found. Ultimately, from this perspective, the best ideal entrainer to be added is the one that only forms one additional minimum-boiling heterogeneous azeotrope with water. As a matter of fact, if we examine the corresponding ternary map, the flowrate of the vapor stream from the top of the heterogeneous azeotropic column would be further reduced.

Hence, in order to compare the entrainers, Figures 5-7 show the ternary diagrams with the material balance lines associated with the heterogeneous azeotropic distillation process. As can be noticed by examining $b$ and $a$ for the various cases, benzene turns out to be the best possible entrainer, followed by isooctane and cyclohexane.

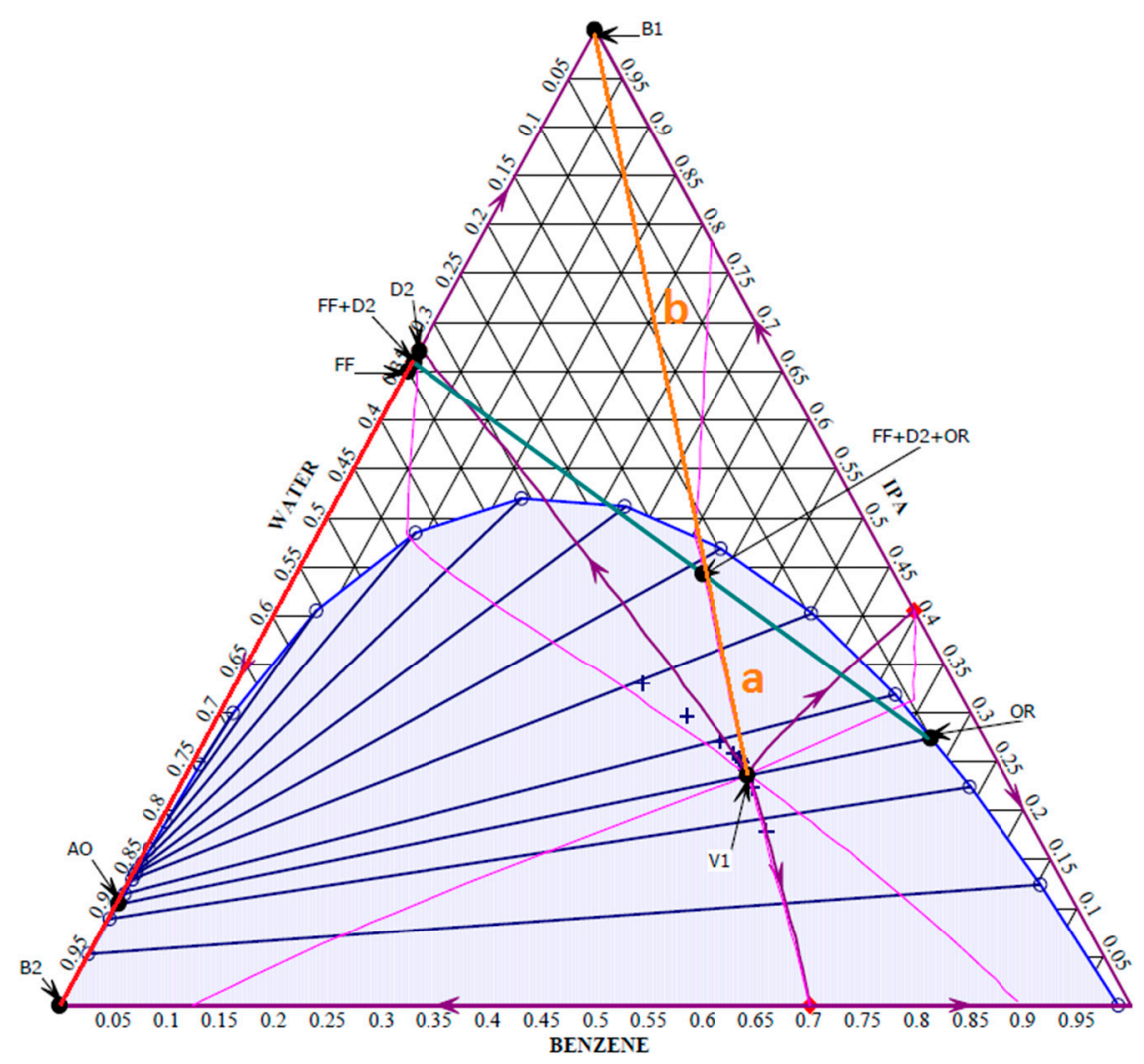

Figure 5. Ternary map at $1 \mathrm{~atm}$ for the system 2-propanol (IPA) + water (WATER) + benzene (BENZENE), showing the points corresponding to the streams involved in the process shown in Figure 1, the material balance line for the HAD column (in orange), segments $a$ and $b$ for the calculation of the $V 1$ flowrate (Equation (1)), and the material balance line for the recovery column (in red). 


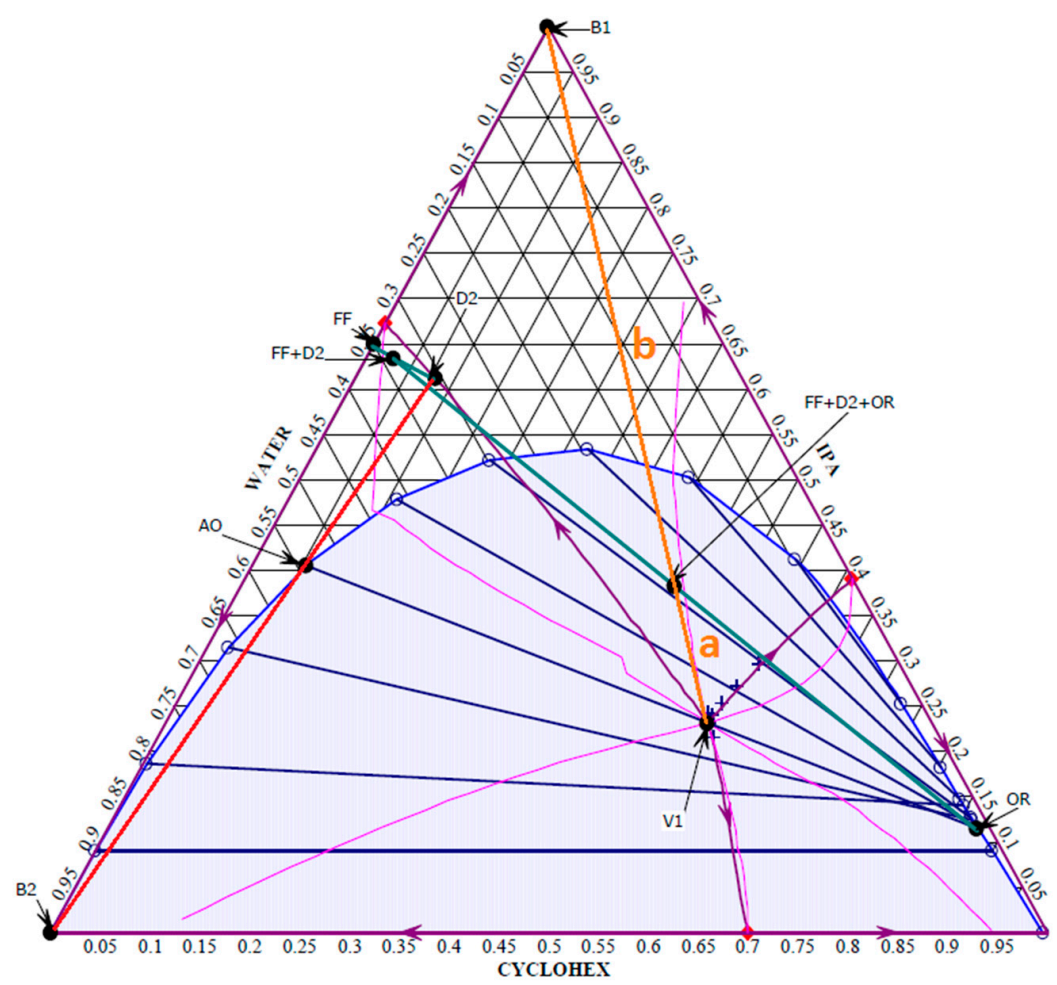

Figure 6. Ternary map at $1 \mathrm{~atm}$ for the system 2-propanol (IPA) + water (WATER) + cyclohexane (CYCLOHEX), showing the points corresponding to the streams involved in the process shown in Figure 1, the material balance line for the HAD column (in orange), segments $a$ and $b$ for the calculation of the $V 1$ flowrate (Equation (1)), and the material balance line for the recovery column (in red).

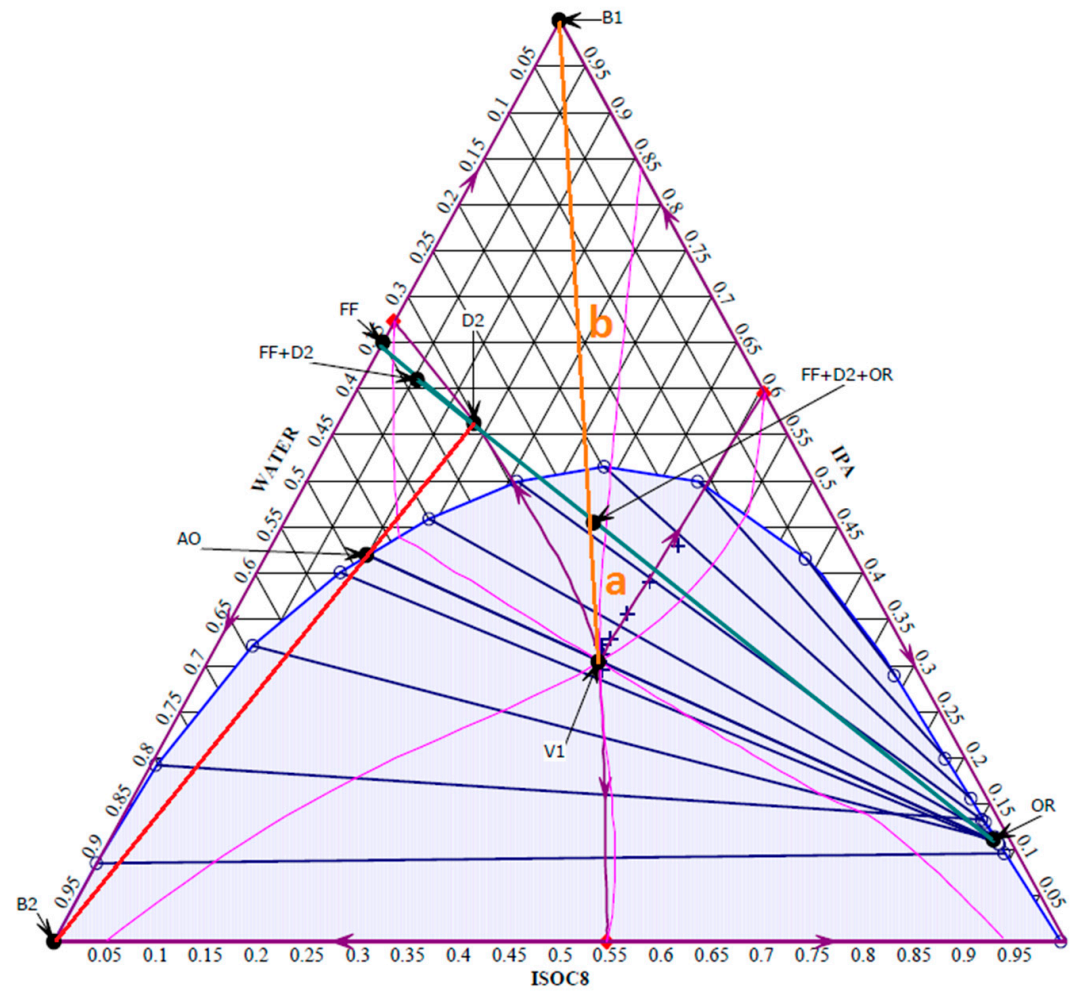

Figure 7. Ternary map at $1 \mathrm{~atm}$ for the system 2-propanol (IPA) + water (WATER) + isooctane (ISOC8), showing the points corresponding to the streams involved in the process shown in Figure 1, the material balance line for the HAD column (in orange), segments $a$ and $b$ for the calculation of the $V 1$ flowrate (Equation (1)), and the material balance line for the recovery column (in red). 
Additional papers can be considered in order to compare the various candidate entrainers $[30,33,37,44,69]$. In particular, with reference to what was reported by Gomis, Pienaar and their co-workers $[30,33,44]$, the comparison of solvent performances should be based on the slope of the tie line passing through the heteroazeotropic point. As a matter of fact, the efficiency of the process is improved when the amount of water eliminated in the decanter of the heterogeneous azeotropic distillation column is greater. Therefore, by considering that the vapor stream exiting the top of the column is close to the heteroazeotropic point, the composition of the aqueous phase of the tie line containing the heteroazeotrope is related to the amount of water eliminated after condensation and decantation: when the water content of the aqueous phase is lower, a larger quantity of all of the components needs to be recirculated within the system (OR stream), with a consequent increase in the operating costs. Thus, by examining the ternary maps shown in Figures 2-4, it can be noticed that the water content in the case of benzene as an entrainer is much higher (ca. $90 \% \mathrm{~mol}$ ) than in the case of cyclohexane (ca. $60 \% \mathrm{~mol}$ ) or isooctane (ca. $58 \% \mathrm{~mol})$. Consequently, benzene can be regarded as the best entrainer for the separation of the 2-propanol + water mixture, whilst, with reference to cyclohexane and isooctane, remarkable differences are not found.

The analysis carried out with the aid of the ternary maps allows the observation that benzene is the most appropriate entrainer as far as the HAD process is concerned for the separation of the mixture under investigation. Nevertheless, as it is carcinogenic, alternative solvents need to be found: in addition to cyclohexane, which was already analyzed in several literature papers (as summarized in Table 2), isooctane can be reasonably taken into consideration. Indeed, cyclohexane and, even more, isooctane do not pose a problem within the recovered alcoholic fraction with a view to its subsequent use as a fuel.

On the contrary, amyl alcohol is not directly comparable to the other entrainers, as it entails the formation of a binary heterogeneous azeotrope, which is not even minimumboiling: the ternary diagram conformation, shown in Figure 8-and, in turn, the required process configuration-are unavoidably different from the ones envisaged so far (as shown in Figures 2-7). Nonetheless, amyl alcohol might be considered as a potential solvent, with its own process configuration, and it might turn out to be even better than benzene, cyclohexane and isooctane, as the water content in the aqueous phase exiting the decanter would be approximately equal to $100 \%$. However, a conflicting aspect has to be unavoidably considered: because the homogeneous 2-propanol + water $(67.28-32.72 \% \mathrm{~mol})$ azeotrope is characterized by a normal boiling point temperature of $80.18^{\circ} \mathrm{C}$, the 2-propanol, with a normal boiling point temperature of $82.05^{\circ} \mathrm{C}$, corresponds to a saddle point. It is, thus, evident that a process configuration involving amyl alcohol as an entrainer cannot work: if we are trying to simulate the heterogeneous azeotropic distillation column in order to obtain the required alcohol from the top and the heteroazeotrope from the bottom, it would not be possible to reach a distillate composition beyond that of the 2-propanol + water homogeneous azeotrope.

As a result of the analysis presented above, isooctane was regarded as a feasible and viable entrainer for the separation of the 2-propanol + water mixture, thus filling the gap existing in the literature due to the lack of studies on the process for the separation of such a mixture using isooctane as an entrainer. 


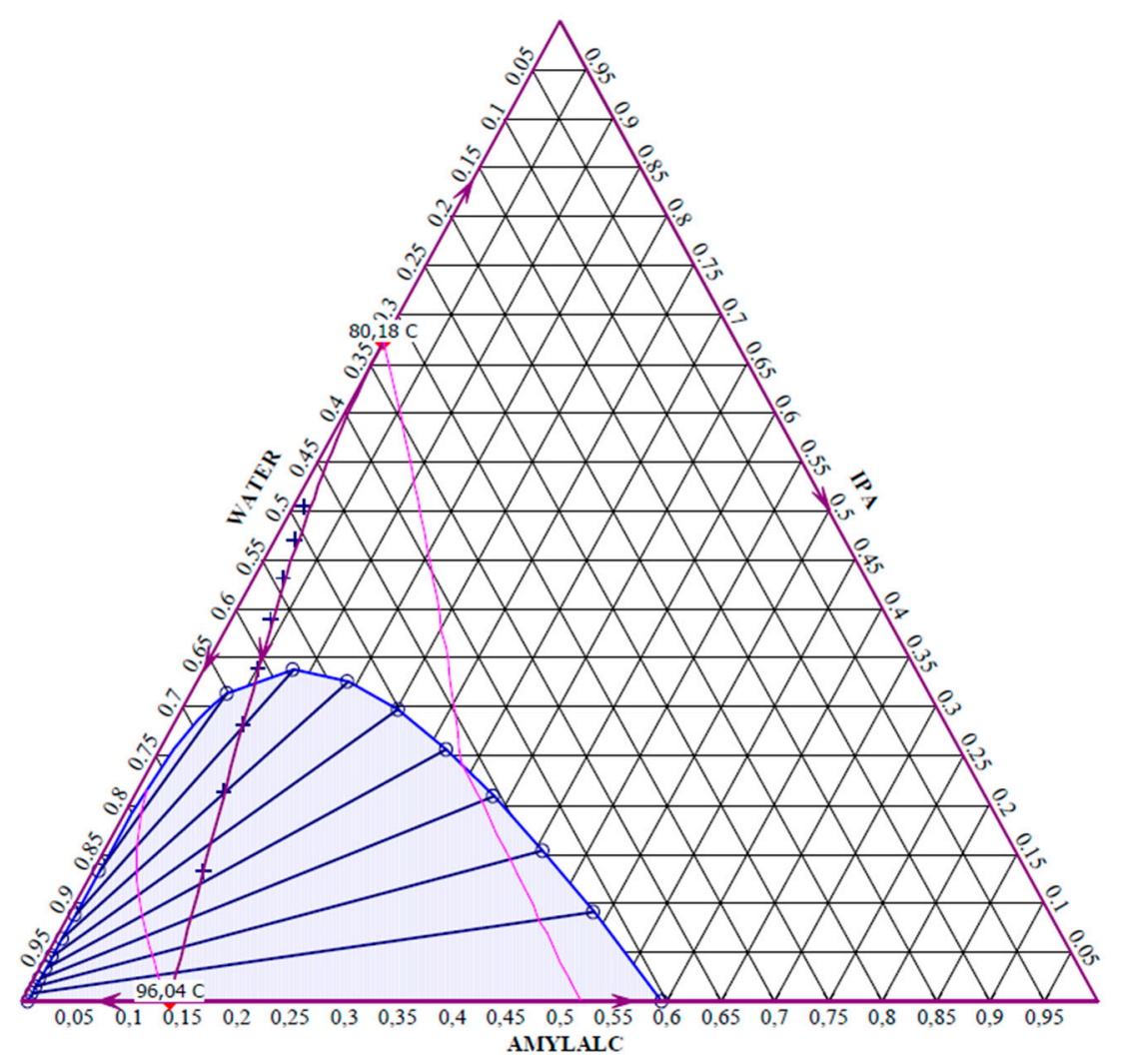

Figure 8. Ternary map at $1 \mathrm{~atm}$, obtained by means of Aspen Plus ${ }^{\circledR}$ V11 [61] using the NRTL model, for the system 2-propanol (IPA) + water (WATER) + amyl alcohol (AMYLALC).

\subsection{Process Simulation}

According to the outcomes of the entrainer selection analysis presented in the previous section, the simulation of the HAD process with the use of isooctane was carried out by means of the Aspen Plus ${ }^{\circledR}$ V11 [61] commercial software.

In more detail, several attempts have been made to properly simulate the configuration and meet the targets related to the 2-propanol product fraction and the aqueous stream: as highlighted by Luyben [24], the simulation of the two columns involved in such a process is extremely challenging because of the need to converge the two recycle streams in a highly non-ideal phase equilibrium system. Consequently, at first, the process configuration shown in Figure 9, with the two recycle streams (REFLUX and RECYCLE) not closed, was simulated: by referring to Luyben's work and by examining the ternary map for the system under investigation, first-guess values were considered for the definition of the REFLUX and RECYCLE streams, and calculated values were obtained (CALCREFL and CALCRECY in Figure 9). As a subsequent step, the first-guess values were manually adjusted in an attempt to reduce, as far as possible, the extremely high variations related to the REFLUX/CALCREFL and RECYCLE/CALCRECY flowrates, composition and temperatures. For this purpose, Aspen Plus Dynamics ${ }^{\circledR}$ was also exploited: the sizing of the process vessels as well as the checking of the pressure levels throughout the flowsheet were carried out, and the process simulation, with all of the pumps and valves required, was exported from Aspen Plus ${ }^{\circledR}$ to Aspen Plus Dynamics ${ }^{\circledR}$. After much effort, the problem of converging the recycle streams and closing the two loops was solved (Figure 10). 


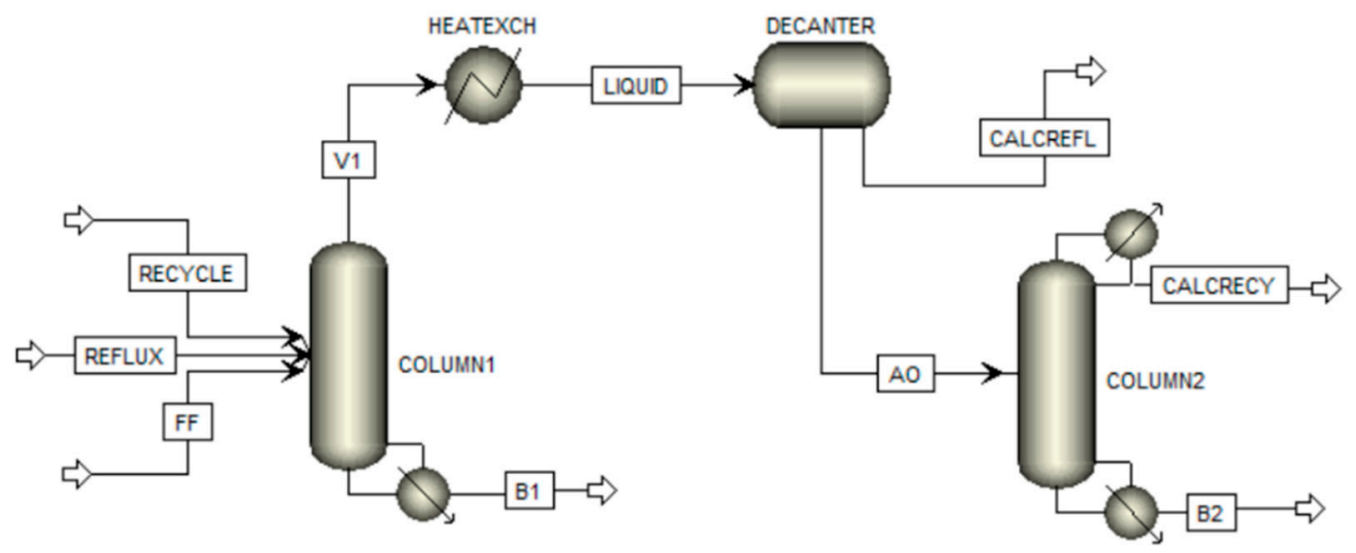

Figure 9. Flowsheet of the HAD process simulated in Aspen Plus ${ }^{\circledR}$ V11 [61] for the separation of the mixture 2-propanol + water using isooctane as an entrainer (with the two loops related to the recycle streams not closed).

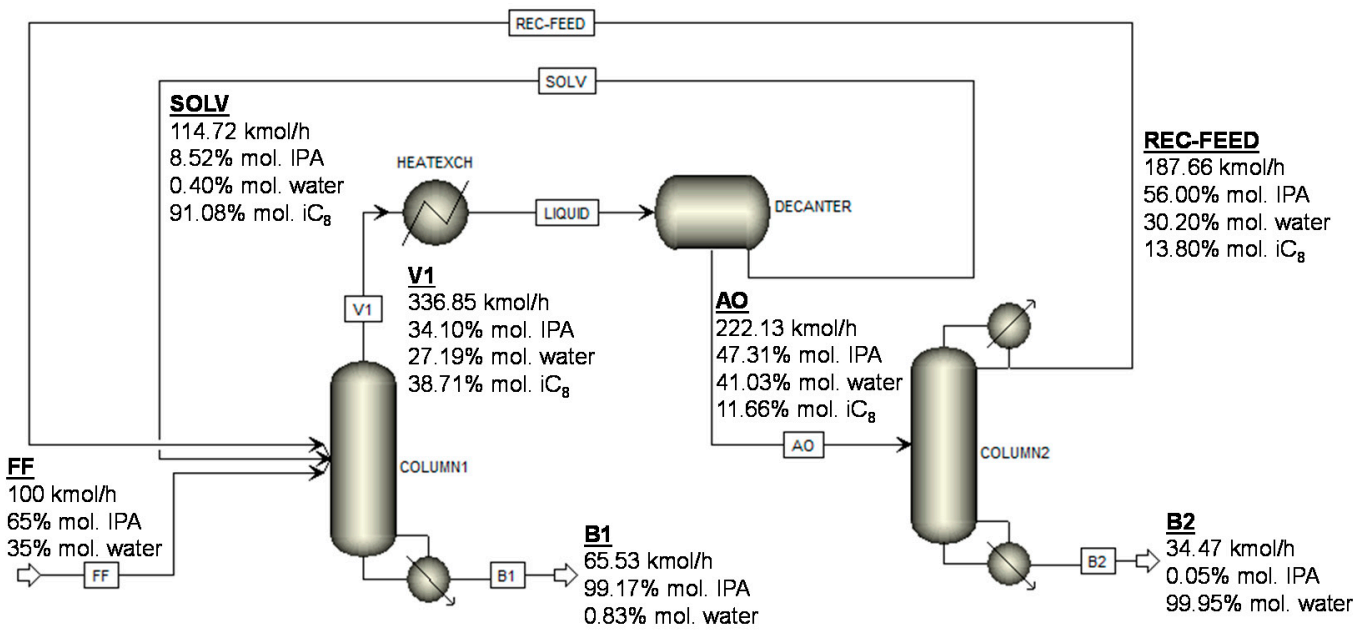

Figure 10. Flowsheet of the HAD process simulated in Aspen Plus ${ }^{\circledR}$ V11 [61] for the separation of the mixture 2-propanol $(\mathrm{IPA})+$ water using isooctane $\left(\mathrm{iC}_{8}\right)$ as an entrainer (with the two loops related to the recycle streams closed).

The results obtained imply that, in the case of $100 \mathrm{kmol} / \mathrm{h}$ of the 2-propanol + water mixture, available at $25^{\circ} \mathrm{C}$, a heteroazeotropic column (COLUMN1) with 30 stages, excluding the condenser, is required. The feed mixture to be separated enters the column at stage number 3 (counting from the top). Instead, the inlet stage for the organic phase (SOLV, $114.72 \mathrm{kmol} / \mathrm{h}$ ) exiting the DECANTER is number 1 , and the inlet stage for the stream (REC-FEED, $187.66 \mathrm{kmol} / \mathrm{h}$ ) exiting the top of the recovery column (COLUMN2) is number 2. Moreover, the diameter of COLUMN1 turns out to be equal to $1.663 \mathrm{~m}$. The energy consumption related to the reboiler is equal to $4.019 \mathrm{MW}$, whilst the duty of the heat exchanger $(\mathrm{HEATEXCH})$ needed for the condensation of the top vapor stream turns out to be $3.529 \mathrm{MW}$.

A decanter (DECANTER) and a recovery column (COLUMN2) with 25 stages are also necessary. The aqueous stream (AO) exiting the decanter enters the column at stage number 10 (counting from the top). In addition, COLUMN2's condenser duty, reboiler duty and diameter turn out to be equal, respectively, to $8.395 \mathrm{MW}, 8.756 \mathrm{MW}$ and $2.122 \mathrm{~m}$.

Further considerations related to the temperature levels at the top and at the bottom of the columns should be made. The HAD process is characterized by COLUMN1's condenser and reboiler being operated at $71.12^{\circ} \mathrm{C}$ and $81.95^{\circ} \mathrm{C}$, respectively: cooling water can be used at the condenser, while even exhaust steam can be used at the reboiler. On the contrary, for COLUMN2, $72.64{ }^{\circ} \mathrm{C}$ is the operating temperature of the condenser and $99.64{ }^{\circ} \mathrm{C}$ is the operating temperature of the reboiler. Thus, cooling water can also be employed at the condenser in this case, and low-pressure steam is required for the operation of the reboiler. 
By applying such a process, the two required targets are met: the water content within the 2-propanol stream is equal to $2500 \mathrm{ppm}$ by weight, whilst the ThOD value of the aqueous stream exiting the bottom of COLUMN2 is estimated to be $3.671 \mathrm{gO}_{2} / \mathrm{L}$. A further consideration is related to the ratio, equal to 3.4, between the flowrate of the aqueous phase (AO) exiting the decanter and entering COLUMN2, and the flowrate of the 2-propanol product stream (B1): evidently, a high flowrate is going from the HAD column to the recovery column, and is recycled back.

Figure 11 summarizes the results obtained by making reference to the ternary map for the system under study: the points corresponding to the various streams in Figure 10 as well as the material balance lines for the two columns are shown.

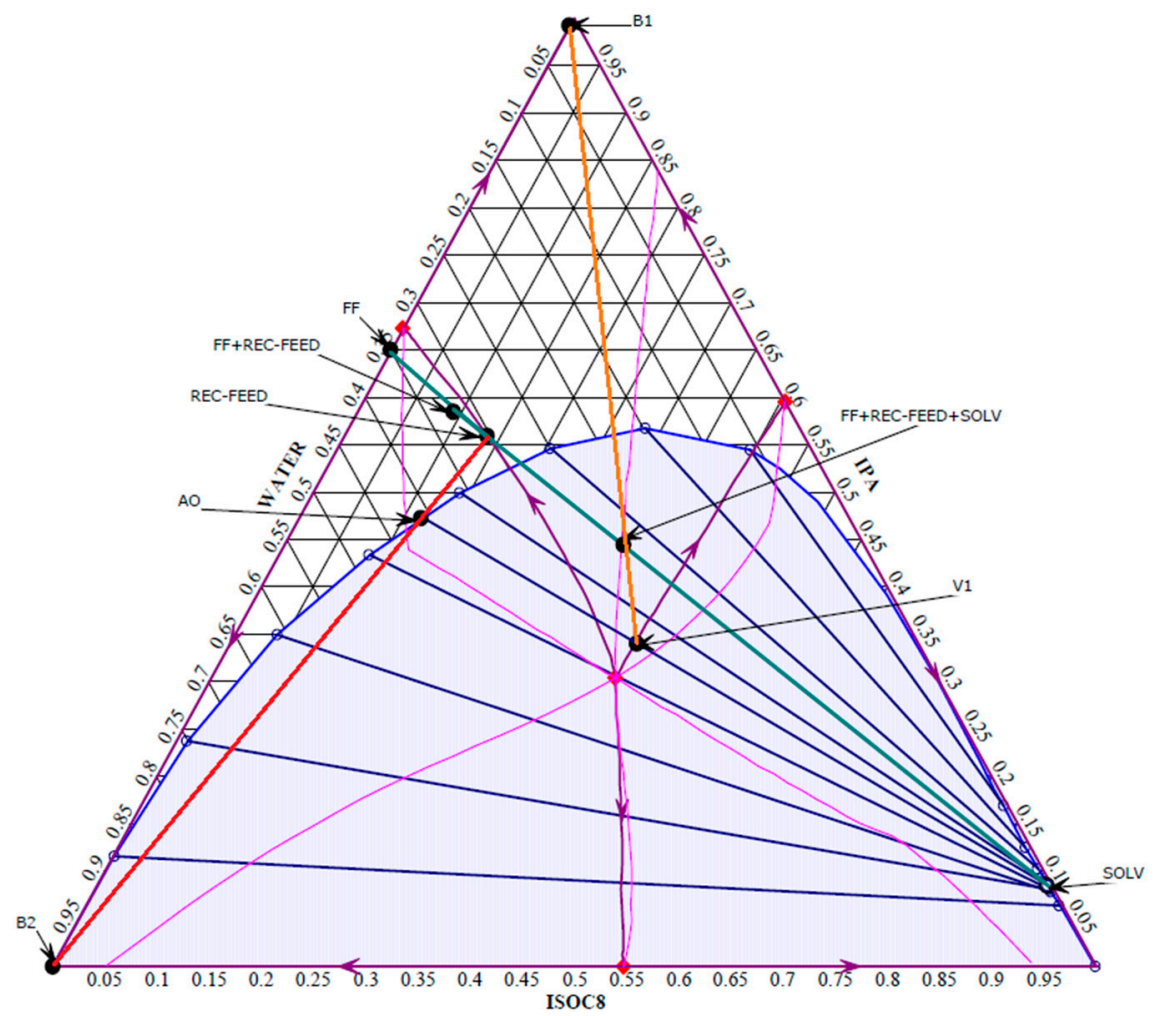

Figure 11. Ternary map at $1 \mathrm{~atm}$ for the system 2-propanol (IPA) + water (WATER) + isooctane (ISOC8), showing the points corresponding to the streams involved in the process illustrated in Figure 10, the material balance line for the HAD column (in orange), and the material balance line for the recovery column (in red).

\section{Conclusions}

The dehydration of azeotropic alcoholic mixtures is essential in downstream separations involved in biofuel production, and alternative processes to conventional distillation need to be considered. In this context, this work was focused on the analysis of the heterogeneous azeotropic distillation (HAD) process, with the aim of dehydrating a 2-propanol + water $(65-35 \% \mathrm{~mol})$ mixture and obtaining an alcoholic product stream to be used as a biofuel. The scope of this work was to fill the gap existing in the pertinent literature due to the analysis of heterogeneous azeotropic distillation processes for the dehydration of aqueous 2-propanol mixtures with the use of isooctane as an entrainer. Indeed, solvents that are typically considered to produce dehydrated 2-propanol streams are benzene and cyclohexane. On the other hand, isooctane is usually employed for the separation of ethanol + water mixtures, whilst the few papers available on 2-propanol + water + isooctane ternaries are related to the examination of the potentialities of such an entrainer for 2-propanol dehydration, without reference to process analysis. 
By referring to the triangular maps of the corresponding ternaries, the performances of various candidate entrainers have been compared: benzene turns out to be the most appropriate entrainer to be used for the separation. Nevertheless, as it is carcinogenic, alternative entrainers are necessary, and in that regard, isooctane can be identified as a feasible and viable option. On the contrary, the possibility of using amyl alcohol as entrainer has to be discarded.

The simulation of the process with the use of isooctane as an entrainer, which was not reported in previous literature works, was carried out by means of the Aspen Plus ${ }^{\circledR}$ V11 commercial simulation software using the NRTL thermodynamic model with built-in parameters. The procedure that was followed to overcome the difficulties experienced in closing the loops related to the two recycle streams to the heteroazeotropic column (namely, the organic phase exiting the decanter and the distillate stream exiting the top of the recovery column) was explained, and the results were discussed with the aid of the corresponding ternary map, which showed the points representing the different streams at stake together with the material balance lines. The simulated process was able to recover 2-propanol with a water content limited to $2500 \mathrm{ppm}$ by weight from the bottom of the first column, and to obtain water from the bottom of the second column at a mole purity of $99.95 \%$ to limit the impact on the downstream water treatment process. Considering $100 \mathrm{kmol} / \mathrm{h}$ of 2-propanol + water mixture to be separated, the energy consumptions are related to the reboiler (4.019 MW) and the condenser (3.529 MW) of the first column, and to the reboiler (8.756 MW) and condenser (8.395 MW) of the second column.

Author Contributions: Methodology, C.M.; Supervision, L.A.P.; Validation, E.S.; Writing-original draft and Writing-review and editing, G.D.G. All authors have read and agreed to the published version of the manuscript.

Funding: This research received no external funding.

Institutional Review Board Statement: Not applicable.

Informed Consent Statement: Not applicable.

Data Availability Statement: The data presented in this study are available within the article.

Conflicts of Interest: The authors declare no conflict of interest.

\section{References}

1. Redel-Macías, M.D.; Leiva-Candia, D.E.; Soriano, J.A.; Herreros, J.M.; Cubero-Atienza, A.J.; Pinzi, S. Influence of short carbonchain alcohol (ethanol and 1-propanol)/diesel fuel blends over diesel engine emissions. Energies 2021, 14, 1309. [CrossRef]

2. Fernández-Rodríguez, D.; Lapuerta, M.; German, L. Progress in the Use of Biobutanol Blends in Diesel Engines. Energies 2021, 14, 3215. [CrossRef]

3. Lodi, G.; De Guido, G.; Pellegrini, L.A. Simulation and energy analysis of the ABE fermentation integrated with gas stripping. Biomass Bioenerg. 2018, 116, 227-235. [CrossRef]

4. Sjulander, N.; Kikas, T. Origin, impact and control of lignocellulosic inhibitors in bioethanol production-A review. Energies 2020, 13, 4751. [CrossRef]

5. Lodi, G.; De Guido, G.; Pellegrini, L. Recovery of butanol from ABE fermentation broth by gas stripping: Process simulation and techno-economic evaluation. In Proceedings of the 25th European Biomass Conference and Exhibition (EUBCE 2017), Stockholm, Sweden, 12-15 June 2017; pp. 1034-1041.

6. De Guido, G.; Lodi, G.; Pellegrini, L. Study of the integrated product recovery by gas stripping for the ABE fermentation with a fed-batch fermenter. Chem. Eng. Trans. 2019, 74, 793-798. [CrossRef]

7. Zhu, T.; Yu, X.; Yi, M.; Wang, Y. Facile covalent crosslinking of zeolitic imidazolate framework/polydimethylsiloxane mixed matrix membrane for enhanced ethanol/water separation performance. ACS Sustain. Chem. Eng. 2020, 8, 12664-12676. [CrossRef]

8. Rossetti, I.; Compagnoni, M.; De Guido, G.; Pellegrini, L.A.; Ramis, G.; Dzwigaj, S. Ethylene production from diluted bioethanol solutions. Can. J. Chem. Eng. 2017, 95, 1752-1759. [CrossRef]

9. Wang, L.; Huang, H.; Chang, Y.; Zhong, C. Integrated High Water Affinity and Size Exclusion Effect on Robust Cu-Based Metal-Organic Framework for Efficient Ethanol-Water Separation. ACS Sustain. Chem. Eng. 2021, 9, 3195-3202. [CrossRef]

10. Fu, C.; Li, Z.; Sun, Z.; Xie, S. A review of salting-out effect and sugaring-out effect: Driving forces for novel liquid-liquid extraction of biofuels and biochemicals. Front. Chem. Sci. Eng. 2021, 15, 854-871. [CrossRef]

11. Haris, A.; Irhamsyah, A.; Permatasari, A.D.; Desa, S.S.; Irfanita, R.; Wahyuni, S. Pervaporation membrane based on laterite zeolite-geopolymer for ethanol-water separation. J. Clean. Prod. 2020, 249, 119413. 
12. Widagdo, S.; Seider, W.D. Journal review. Azeotropic distillation. AIChE J. 1996, 42, 96-130. [CrossRef]

13. Moussa, A.S.; Jiménez, L. Entrainer selection and systematic design of heterogeneous azeotropic distillation flowsheets. Ind. Eng. Chem. Res. 2006, 45, 4304-4315. [CrossRef]

14. Cairns, B.P.; Furzer, I.A. Multicomponent three-phase azeotropic distillation. 2. Phase-stability and phase-splitting algorithms. Ind. Eng. Chem. Res. 1990, 29, 1364-1382. [CrossRef]

15. Kraemer, K.; Harwardt, A.; Skiborowski, M.; Mitra, S.; Marquardt, W. Shortcut-based design of multicomponent heteroazeotropic distillation. Chem. Eng. Res. Des. 2011, 89, 1168-1189. [CrossRef]

16. Pham, H.N.; Doherty, M.F. Design and synthesis of heterogeneous azeotropic distillations-I. Heterogeneous phase diagrams. Chem. Eng. Sci. 1990, 45, 1823-1836. [CrossRef]

17. Pham, H.N.; Doherty, M.F. Design and synthesis of heterogeneous azeotropic distillations-II. Residue curve maps. Chem. Eng. Sci. 1990, 45, 1837-1843. [CrossRef]

18. Pham, H.N.; Doherty, M.F. Design and synthesis of heterogeneous azeotropic distillations-III. Column sequences. Chem. Eng. Sci. 1990, 45, 1845-1854. [CrossRef]

19. Prayoonyong, P.; Jobson, M. Flowsheet synthesis and complex distillation column design for separating ternary heterogeneous azeotropic mixtures. Chem. Eng. Res. Des. 2011, 89, 1362-1376. [CrossRef]

20. Ryan, P.J.; Doherty, M.F. Design/optimization of ternary heterogeneous azeotropic distillation sequences. AIChE J. 1989, 35, 1592-1601. [CrossRef]

21. Chien, I.; Wang, C.; Wong, D. Dynamics and control of a heterogeneous azeotropic distillation column: Conventional control approach. Ind. Eng. Chem. Res. 1999, 38, 468-478. [CrossRef]

22. Chien, I.-L.; Chen, W.-H.; Chang, T.-S. Operation and decoupling control of a heterogeneous azeotropic distillatin column. Comput. Chem. Eng. 2000, 24, 893-899. [CrossRef]

23. Kovach, J., III; Seider, W. Heterogeneous azeotropic distillation: Experimental and simulation results. AIChE J. 1987, 33, 1300-1314. [CrossRef]

24. Luyben, W.L. Control of a multiunit heterogeneous azeotropic distillation process. AIChE J. 2006, 52, 623-637. [CrossRef]

25. Luyben, W.L. Control of the heterogeneous azeotropic n-butanol/water distillation system. Energy Fuels 2008, 22, 4249-4258. [CrossRef]

26. Wang, C.; Wong, D.; Chien, I.; Shih, R.; Liu, W.; Tsai, C. Critical reflux, parametric sensitivity, and hysteresis in azeotropic distillation of isopropyl alcohol+ water+ cyclohexane. Ind. Eng. Chem. Res. 1998, 37, 2835-2843. [CrossRef]

27. Cairns, B.P.; Furzer, I.A. Multicomponent three-phase azeotropic distillation. 3. modern thermodynamic models and multiple solutions. Ind. Eng. Chem. Res. 1990, 29, 1383-1395. [CrossRef]

28. Font, A.; Asensi, J.C.; Ruiz, F.; Gomis, V. Application of isooctane to the dehydration of ethanol. Design of a column sequence to obtain absolute ethanol by heterogeneous azeotropic distillation. Ind. Eng. Chem. Res. 2003, 42, 140-144. [CrossRef]

29. Gomis, V.; Pedraza, R.; Francés, O.; Font, A.; Asensi, J.C. Dehydration of ethanol using azeotropic distillation with isooctane. Ind. Eng. Chem. Res. 2007, 46, 4572-4576. [CrossRef]

30. Pienaar, C. Evaluation of Entrainers for the Dehydration of $C_{2}$ and $C_{3}$ Alcohols Via Azeotropic Distillation. Master's Thesis, Stellenbosch University, Stellenbosch, South Africa, 2012.

31. Zhao, L.; Lyu, X.; Wang, W.; Shan, J.; Qiu, T. Comparison of heterogeneous azeotropic distillation and extractive distillation methods for ternary azeotrope ethanol/toluene/water separation. Comput. Chem. Eng. 2017, 100, 27-37. [CrossRef]

32. Gomis, V.; Font, A.; Saquete, M.D. Vapour-liquid-liquid and vapour-liquid equilibrium of the system water+ ethanol+ heptane at $101.3 \mathrm{kPa}$. Fluid Ph. Equilibria 2006, 248, 206-210. [CrossRef]

33. Gomis, V.; Font, A.; Pedraza, R.; Saquete, M. Isobaric vapor-liquid and vapor-liquid-liquid equilibrium data for the waterethanol-hexane system. Fluid Ph. Equilibria 2007, 259, 66-70. [CrossRef]

34. Pequenin, A.; Asensi, J.C.; Gomis, V. Isobaric vapor- liquid-liquid equilibrium and vapor- liquid equilibrium for the quaternary system water- ethanol- cyclohexane- isooctane at $101.3 \mathrm{kPa}$. J. Chem. Eng. Data 2010, 55, 1227-1231. [CrossRef]

35. Pequenín, A.; Asensi, J.C.; Gomis, V. Quaternary isobaric (vapor + liquid + liquid) equilibrium and (vapor + liquid) equilibrium for the system (water+ethanol + cyclohexane + heptane) at $101.3 \mathrm{kPa}$. J. Chem. Thermodyn. 2011, 43, 1097-1103. [CrossRef]

36. Pequenín, A.; Asensi, J.C.; Gomis, V. Vapor-liquid-liquid equilibrium and vapor-liquid equilibrium for the quaternary system water-ethanol-cyclohexane-toluene and the ternary system water-cyclohexane-toluene. Isobaric experimental determination at $101.3 \mathrm{kPa}$. Fluid Ph. Equilibria 2011, 309, 62-67. [CrossRef]

37. Chien, I.-L.; Zeng, K.-L.; Chao, H.-Y. Design and control of a complete heterogeneous azeotropic distillation column system. Ind. Eng. Chem. Res. 2004, 43, 2160-2174. [CrossRef]

38. Arifin, S.; Chien, I.-L. Combined preconcentrator/recovery column design for isopropyl alcohol dehydration process. Ind. Eng. Chem. Res. 2007, 46, 2535-2543. [CrossRef]

39. Luyben, W.L.; Chien, I.-L. Design and Control of Distillation Systems for Separating Azeotropes; John Wiley \& Sons: Hoboken, NJ, USA, 2010.

40. Cho, J.; Jeon, J.-K. Optimization study on the azeotropic distillation process for isopropyl alcohol dehydration. Korean J. Chem. Eng. 2006, 23, 1-7. [CrossRef]

41. Arda, N.; Sayar, A.A. Liquid-liquid equilibrium of water+ 2-propanol+ 2, 2, 4-trimethylpentane ternary at $293.2 \pm 0.1 \mathrm{~K}$. Fluid Ph. Equilibria 1992, 73, 129-138. [CrossRef] 
42. Otero, J.; Comesana, J.; Correa, J.; Correa, A. Liquid-liquid equilibria of the system water+ 2-propanol+ 2, 2, 4-trimethylpentane at 25 C. J. Chem. Eng. Data 2000, 45, 898-901. [CrossRef]

43. Gomis, V.; Font, A.; Saquete, M.; García-Cano, J. LLE, VLE and VLLE data for the water-n-butanol-n-hexane system at atmospheric pressure. Fluid Ph. Equilibria 2012, 316, 135-140. [CrossRef]

44. Pienaar, C.; Schwarz, C.E.; Knoetze, J.H.; Burger, A.J. Vapor-liquid-liquid equilibria measurements for the dehydration of ethanol, isopropanol, and n-propanol via azeotropic distillation using dipe and isooctane as entrainers. J. Chem. Eng. Data 2013, 58, 537-550. [CrossRef]

45. Gomis, V.; Font, A.; Pedraza, R.; Saquete, M. Isobaric vapor-liquid and vapor-liquid-liquid equilibrium data for the system water+ ethanol+ cyclohexane. Fluid Ph. Equilibria 2005, 235, 7-10. [CrossRef]

46. Gomis, V.; Pequenín, A.; Asensi, J.C. Isobaric vapor-liquid-liquid equilibrium and vapor-liquid equilibrium for the system water-ethanol-1, 4-dimethylbenzene at $101.3 \mathrm{kPa}$. Fluid Ph. Equilibria 2009, 281, 1-4. [CrossRef]

47. Gomis, V.; Pequenín, A.; Asensi, J.C. A review of the isobaric (vapor + liquid + liquid) equilibria of multicomponent systems and the experimental methods used in their investigation. J. Chem. Thermodyn. 2010, 42, 823-828. [CrossRef]

48. Hölscher, I.; Schneider, G.; Ott, J. Liquid-liquid phase equilibria of binary mixtures of methanol with hexane, nonane and decane at pressures up to $150 \mathrm{MPa}$. Fluid Ph. Equilibria 1986, 27, 153-169. [CrossRef]

49. Hwang, I.-C.; Park, S.-J.; Choi, J.-S. Liquid-liquid equilibria for the binary system of di-isopropyl ether (DIPE)+ water in between 288.15 and $323.15 \mathrm{~K}$ and the ternary systems of DIPE + water $+C_{1}-C_{4}$ alcohols at 298.15 K. Fluid Ph. Equilibria 2008, 269, 1-5. [CrossRef]

50. Lladosa, E.; Montón, J.B.; Burguet, M.; de la Torre, J. Isobaric (vapour + liquid + liquid) equilibrium data for (di-n-propyl ether + n-propyl alcohol + water) and (diisopropyl ether + isopropyl alcohol + water) systems at $100 \mathrm{kPa}$. J. Chem. Thermodyn. 2008, 40, 867-873. [CrossRef]

51. Rastegar, R.; Jessen, K. Measurement and Modeling of Liquid-Liquid Equilibrium for Ternary and Quaternary Mixtures of Water, Methanol, 2-Propanol, and 2,2,4-Trimethylpentane at 293.2 K. J. Chem. Eng. Data 2011, 56, 278-281. [CrossRef]

52. Sayar, A.A. Liquid-liquid equilibria of some water + 2-propanol + solvent ternaries. J. Chem. Eng. Data 1991, 36, 61-65. [CrossRef]

53. Tamura, K.; Chen, Y.; Tada, K.; Yamada, T. Liquid-liquid equilibria for quaternary mixtures of water, ethanol, and 2,2,4trimethylpentane with fuel additives. Fluid Ph. Equilibria 2000, 171, 115-126. [CrossRef]

54. Verhoeye, L.A.J. System cyclohexane-2-propanol-water. J. Chem. Eng. Data 1968, 13, 462-467. [CrossRef]

55. Wang, C.; Chen, Y.; Ying, A. Measurement and Calculation of Liquid-Liquid Equilibria of Ternary and Quaternary Systems Containing Water, Propan-1-ol, and 2,2,4-Trimethylpentane (TMP) with 2,2'-Oxybis(propane) (DIPE) or Dimethyl Carbonate (DMC). J. Chem. Eng. Data 2011, 56, 4466-4472. [CrossRef]

56. Asensi, J.C.; Moltó, J.; del Mar Olaya, M.a.; Ruiz, F.; Gomis, V. Isobaric vapour-liquid equilibria data for the binary system 1-propanol+1-pentanol and isobaric vapour-liquid-liquid equilibria data for the ternary system water+1-propanol+1-pentanol at 101.3 kPa. Fluid Ph. Equilibria 2002, 200, 287-293. [CrossRef]

57. Fernández, M.J.; Gomis, V.; Ramos, M.; Ruíz, F. Influence of the Temperature on the Liquid-Liquid Equilibrium of the Ternary System 1-Pentanol + 1-Propanol + Water. J. Chem. Eng. Data 2000, 45, 1053-1054. [CrossRef]

58. Fernández-Torres, M.J.; Gomis-Yagües, V.; Ramos-Nofuentes, M.; Ruíz-Beviá, F. The influence of the temperature on the liquidliquid equilibrium of the ternary system 1-pentanol-ethanol-water. Fluid Ph. Equilibria 1999, 164, 267-273. [CrossRef]

59. Loras, S.; Fernández-Torres, M.J.; Gomis-Yagües, V.; Ruíz-Beviá, F. Isobaric vapor-liquid equilibria for the system 1-pentanol-1propanol-water at $101.3 \mathrm{kPa}$. Fluid Ph. Equilibria 2001, 180, 205-210. [CrossRef]

60. Mara, K.; Bhethanabotla, V.R.; Campbell, S.W. Total pressure measurements for 1-propanol + 1-pentanol, 1-propanol + 2-pentanol, 2-propanol + 1-pentanol, and 2-propanol + 2-pentanol at 313.15 K. Fluid Ph. Equilibria 1997, 127, 147-153. [CrossRef]

61. AspenTech. Aspen Plus®; AspenTech: Burlington, MA, USA, 2019.

62. Gomis, V.; Font, A.; Saquete, M.D. Homogeneity of the water+ ethanol+ toluene azeotrope at 101.3 kPa. Fluid Ph. Equilibria 2008, 266, 8-13. [CrossRef]

63. Gomis, V.; Ruiz, F.; Asensi, J.C. The application of ultrasound in the determination of isobaric vapour-liquid-liquid equilibrium data. Fluid Ph. Equilibria 2000, 172, 245-259. [CrossRef]

64. Magnussen, T.; Michelsen, M.; Fredenslund, A. Azeotropic distillation using UNIFAC. Inst. Chem. Eng. Symp. Ser. 1979, 56, 1-4.

65. Newsham, D.; Vahdat, N. Prediction of vapour-liquid-liquid equilibria from liquid-liquid equilibria Part I: Experimental results for the systems methanol-water-n-but. Chem. Eng. J. 1977, 13, 27-31. [CrossRef]

66. Iwakabe, K.; Kosuge, H. Isobaric vapor-liquid-liquid equilibria with a newly developed still. Fluid Ph. Equilibria 2001, 192, 171-186. [CrossRef]

67. Van Zandijcke, F.; Verhoeye, L. The vapour-liquid equilibrium of ternary systems with limited miscibility at atmospheric pressure. J. Appl. Chem. Biotechnol. 1974, 24, 709-729. [CrossRef]

68. Lee, L.-S.; Chen, W.-C.; Huang, J.-F. Experiments and correlations of phase equilibria of ethanol-ethyl acetate-water ternary mixture. J. Chem. Eng. Jpn. 1996, 29, 427-438. [CrossRef]

69. Donis, I.R.; Esquijarosa, J.A.; Gerbaud, V.; Joulia, X. Heterogeneous batch-extractive distillation of minimum boiling azeotropic mixtures. AIChE J. 2003, 49, 3074-3083. [CrossRef] 
70. Younis, O.; Pritchard, D.; Anwar, M. Experimental isobaric vapour-liquid-liquid equilibrium data for the quaternary systems water (1)-ethanol (2)-acetone (3)-n-butyl acetate (4) and water (1)-ethanol (2)-acetone (3)-methyl ethyl ketone (4) and their partially miscible-constituent ternaries. Fluid Ph. Equilibria 2007, 251, 149-160. [CrossRef]

71. Prokopakis, G.J.; Seider, W.D.; Ross, B. Azeotropic distillation towers with two liquid phases. In Foundations of Computer-Aided Chemical Process Design, Proceedings of the International Conference, Held at New England College, Henniker, New Hampshire, 6-11 July 1980; American Institute of Chemical Engineers: New York, NY, USA, 1981; p. 239.

72. Font, A.; Asensi, J.C.; Ruiz, F.; Gomis, V. Isobaric Vapor- Liquid and Vapor- Liquid- Liquid equilibria data for the system water+ isopropanol+ isooctane. J. Chem. Eng. Data 2004, 49, 765-767. [CrossRef]

73. Aicher, T.; Bamberger, T.; Schluender, E.-U. Liquid-liquid and vapor-liquid phase equilibria for 1-butanol+ water+ 2-propanol at ambient pressure. J. Chem. Eng. Data 1995, 40, 696-698. [CrossRef] 